\title{
UN BANQUERO CATALÁN QUE SE PASEÓ POR EL MUNDO Y CAMBIO ESPAÑA
}

\author{
LUIS TORRAS CONSOLACIÓN*
}

Fecha de recepción: 16 de diciembre de 2014.

Fecha de aceptación: 15 de diciembre de 2015.

Dejo escrito Benjamin Disraeli que con respecto a la historia «mucha atención se ha prestado a los sistemas y muy poca a las personas.» La Historia no puede ser únicamente el resultado de interpretaciones holísticas, resulta igualmente importante tener en consideración el papel que juegan personas concretas que, buscando alcanzar sus objetivos individuales a través del talento, la voluntad y el trabajo, transforman su época y marcan el camino para generaciones venideras.

En España, históricamente, se ha prestado más bien poca atención a nuestros héroes, prueba de ello es la relativamente pequeña extensión de nuestro género biográfico y el prácticamente inexistente género epistolar o memorias de grandes políticos y empresarios de tiempos pretéritos. Sin embargo, en estos tiempos de desconcierto colectivo, poder disponer de puntos de anclaje férreos, especialmente en lo empresarial y económico, además de resultar moralmente gratificante, puede resultar esencial para no naufragar en momentos de gran zozobra colectiva como el actual.

En 1777, un año después de la declaración de Independencia de las trece colonias británicas en América o de la publicación de $L a$ riqueza de las naciones de Adam Smith, nace en Arenys de Mar el futuro empresario, naviero, banquero y benefactor ilustre Josep Xifré i Casas. Se trata de uno de tantos otros empresarios indianos

\footnotetext{
* Socio de Reliance Partners. Miembro del Instituto Ludwig von Mises de Barcelona y miembro del Consejo Asesor del Instituto Juan de Mariana. Dedicado y con todo el agradecimiento a R., amigo y preceptor, quién primero me puso tras la pista del héroe Xifré.
} 
catalanes que harán fortuna dentro y fuera de los dominios del entonces imperio español. Xifré se convertiría en el paradigma de todos ellos. Exponente claro de aquella generación que vivirá a caballo entre el siglo XVIII y el XIX y sin la que es imposible entender la transformación profunda e importantísima que realizará Barcelona y Catalunya en las postrimerías del siglo XIX en el ámbito económico y financiero y que, al mismo tiempo, constituye pieza esencial - aunque a menudo olvidada - para la correcta comprensión y emergencia del ulterior movimiento político catalanista que desde entonces marcará de manera definitoria los avatares políticos de la península.

De joven, Xifré verá como su padre, un próspero naviero y comerciante de Arenys, se arruinará y caerá en desgracia cuando en 1782 dos de sus cuatro bergantines serán hundidos en aguas del Atlántico por la flota británica en el contexto de guerra que entonces enfrentaba a españoles e ingleses. La delicada situación familiar, que acabará con el destierro y muerte prematura del patriarca, obligará al joven Xifré a buscar nuevas oportunidades lejos de su entorno próximo. En 1798, con 21 años, embarcará por primera vez con destino a las Antillas. En Cuba, nuestro joven héroe se valdrá de los contactos familiares en la isla para ponerse a trabajar como peón en una fábrica de muebles. Estos infortunios iniciales y el hecho de empezar desde muy abajo no serán óbice para que una persona dotada de gran visión, perseverante y con gran talento para los negocios se acabe convirtiendo al final de su vida en una de las personas más acaudaladas de Europa.

Rápidamente escalará posiciones gracias a su capacidad de trabajo y su habilidad para comerciar y ganarse la confianza de sus socios que incluirán importantes prohombres de la época como Gaspar de Remisa con quién hará negocios muy lucrativos aprovechando la compleja situación política durante la Guerra de Independencia Española (1808-14). Tras la caída paulatina de los dominios coloniales de España - una caída en dominó que tendrá su detonante en la liberación Americana del dominio inglés-, el grueso del comercio con las colonias se irá concentrando en las Antillas, principalmente en Cuba, estrechando poco a poco los márgenes de las lucrativas industrias de ultramar. En la década de los años veinte Xifré, que ya gozaba de una posición asentada en 
diversos sectores en la isla, irá poniendo la vista cada vez más hacia los incipientes mercados americanos y en la pujante ciudad de Nueva York que conocía por abastecerla de diversos productos —-se tienen anotaciones de Xifré en Nueva York desde 1812-. Xifré se instalará de forma definitiva en la Isla de Manhattan — ciudad entonces en pleno proceso de ebullición- en el año 1823 (la misma época que la célebre película Gangs of New York de Martin Scorsese), en una casa en el número 343 de Greenwich Street desde donde operará todos sus negocios (la calle se corresponde con la actual ubicación en lower Manhattan, muy cerca de las también históricas calles de Church Street y Broadway).

La actividad de Xifré i Casas en Nueva York será frenética: participará como accionista en diferentes bancos, incluyendo el Second Bank of the United States, será presidente de la Cámara de Navegación y Cabotaje de Nueva York y participará de lucrativos negocios inmobiliarios (siendo algo así como un Donald Trump de la época). Xifré establecerá provechosas relaciones de confianza con importantes hombres de negocios de la ciudad y tejerá una importantísima y fructífera relación de contactos (será socio, entre otros, y buen amigo de Guideon Lee que acabará siendo alcalde de la ciudad en el 33, con Xifré ya en Europa) y sociedades que le permitirán participar de forma activa en la construcción y desarrollo de la que, un siglo más tarde, desbancaría a Londres como la ciudad más importante del mundo. Xifré, desarrollará un rol muy activo en la construcción del canal Hudson-Eire, infraestructura clave, aún hoy, en el transporte de materias primas que necesita la ciudad y que conectará su industria textil, curtidora y peletera con los lucrativos mercados del norte. Xifré también participará de forma activa representando los intereses de los ciudadanos residentes en la elaboración de las leyes del recién creado Estado de Nueva York con capital en Albany.

Se trata de años de aprendizaje. Xifré i Casas será uno de tantos catalanes centrífugos, es decir, que buscarán dar salida a su impulso creativo y empresarial fuera del cobijo y protección de la corte después de la derrota de 1714, como si por ejemplo lo hará, otro catalán ilustre de la época, socio del Marqués de Salamanca, y compañero puntual de Xifré en algunas empresas, Gaspar de Remisa. De regreso a su patria natal — «roda el món, torna al born», 
se decía entonces - aplicará todas estas ideas para transformar la ciudad de Barcelona, Catalunya y también España.

Durante los años en Nueva York nuestro héroe se casará con Judith Downing — de la que se dice fue la inspiradora de Flaubert para escribir Madame Bovary o la ópera Carmen con libreto de su íntimo Merimée y música de Bizet, y cuya vida daría para una biografía aún más extensa que la de su ilustre y visionario marido-, hija de uno de sus socios americanos. Xifré nunca perderá de vista su identidad ni sus raíces manteniendo el contacto con Barcelona y Arenys de Mar donde enviará importantes sumas de dinero para financiar obras de beneficencia y filantropía, antes incluso de que importantes nombres de la revolución industrial americana como Carnegie o Rockefeller popularizasen este tipo de comportamientos y actitudes mucho después.

Sin embargo, el hecho de mantener de manera tan clara su identidad catalana y española chocaba de forma frontal con el nuevo paradigma imperante a finales de los veinte cuando el presidente James Monroe promulgó la célebre doctrina que lleva su nombre. En resumen, américa para los americanos. En 1828, con 51 años, Xifré, cansado de continuos ataques tanto por parte del presidente Monroe como del furibundo Quincy Adams, decide abandonar Estados Unidos y volver a Europa vía Londres primero, Paris después. Más tarde, en 1831, regresa a Barcelona y Arenys de Mar ubi bene, ibi patria - por primera vez desde que se marchó siendo recibido con grandes honores. De nuevo: «roda el món i torna al born». La vida de Xifré i Casas transcurrirá exactamente así.

En aquel entonces, según los archivos de Arenys de Mar, la fortuna del ya célebre indiano supera los 30 millones de pesetas de la época convirtiéndole en una de las personas más acaudaladas de Europa. Fortuna que seguirá aumentando hasta el final de sus días dejando un patrimonio líquido superior al patrimonio líquido dejado en herencia por los otros dos catalanes más ricos de la época juntos: Safont y, del ya mencionado, Remisa. Muestra de este gran patrimonio será la construcción del Hospital de Arenys cedido al ayuntamiento en 1849 con un valor total de cinco millones de pesetas de la época, la obra de filantropía más importante del momento, y un proyecto que, aún hoy, resulta algo sobredimensionado con respecto a la población del munici- 
pio. Antes hará más cosas que será reflejo de sus aprendizajes anteriores.

En Barcelona, enseguida tomará posiciones inmobiliarias como hizo cuando llegó a Nueva York-. En aquel entonces, 1831, Barcelona es una ciudad enclaustrada dentro de sus propias murallas y muy insalubre. De hecho, Judith, su mujer, nunca llegará a vivir en Barcelona, sino que se instalará en Paris donde organiza envidiadas fiestas e influyentes reuniones alternando con Napoleón III, la Montijo y la mejor élite europea: nobles, políticos, empresarios, potentados rusos, científicos, músicos, literatos y pintores, todos pasan por su palacio hasta su muerte, viviendo así una vida intensa y rica que amplió, incluso desmesuradamente, la legendaria imagen de poder económico y magna influencia de su marido. Era recordada en París como una inteligente y lúbrica Litith, pero también supo demostrarse como buena esposa. Acompañó solícitamente, durante los tres últimos años de vida a su marido cuidándolo cuando él dejo de valerse por sí mismo. Vivieron en una torre apartada, a las afueras de aquella Barcelona que Judith-Júlia odiaba en lo más hondo por pacata y provinciana.

En 1835 se inician las obras del que será el legado de Xifré más icónico: la Casa Xifré, o los famosos «porxos del Xifré». Será el edificio más moderno de su época en la península siendo modelo - antes que el Palacio Real en Madrid- para el primer daguerrotipo realizado en España por el académico Monlau. Será el primer inmueble en incorporar depósitos en la azotea llenados mediante máquina de vapor y con calefacción central y ¡dos grifos! (de agua caliente y fría), el desconocido hasta entonces water-closet sanitario — que nada tenía que ver con las atávicas e insanas comunas-y la cocina termosifón de hierro fundido Franklin entre otras novedades, todas ellas traídas de fuera. Las raras tuberías de plomo para poder realizar tan moderna y atrevida instalación, se las vendió un ambicioso joven representante llamado Manuel Girona y Agrafel, hermanastro menor de su amigo Joan Girona, desconocido mecanicista industrial y poliglota que, junto con Ramon Bonaplata y Erasme Janer, introdujeron y divulgaron el uso del vapor dando inicio a la revolución industrial en el cinturón de Barcelona.

Este edificio, libre de murallas y ultramoderno, frente a la Llotja de Mar, se convertía en el primer baluarte de la modernidad 
Barcelona de la mano del recién urbanizado paseo de Isabel II. En este edificio hoy encontramos el afamado y clásico restaurante de «Les Set Portes», uno de los focos de riqueza gastronómica y cultural del país que sigue cumpliendo con las funciones que Josep $\mathrm{Xi-}$ fré quiso darle: una café burgués, punto de encuentro para el intercambio de ideas y la socialización de empresarios y librepensadores como ya viese durante su etapa de formación en Nueva York, Londres o Paris. Casa Xifré, y la colindante Casa Vidal-Quadras (perteneciente a otro indiano), serán de las primeras edificaciones extra-muros de la Barcelona moderna.

Al mismo tiempo, desde dentro, un joven secretario del ayuntamiento Manuel Durán i Bas, futuro Ministro de Gracia y Justicia en su madurez, se peleaba con Madrid por liberar a su ciudad de tan penoso y mortal cinturón que encorsetaba las aspiraciones de la que luego sería la primera (y hasta la fecha única) ciudad olímpica en España. Todo esto, años antes de que Idelfonso Cerdá, que será uno de los muchos inquilinos célebres de Xifré (otro, por ejemplo, será Lesseps quién, años más tarde, contará con financiación de Xifré Jr. para la financiación del Canal Suez), proyecte su ya icónico ensanche. ¿Casualidad o causalidad?

Durante estos años Xifré se dedicará a inspirar a toda una generación de jóvenes y a dinamizar el entorno social, económico, financiero, político y cultural de Barcelona, extendiendo su influencia también fuera de España. Acumulará diversos cargos e impulsará diferentes iniciativas. En el 1841, impulsará y será nombrado primer presidente de la Caja de Pensiones Monte de Piedad de Barcelona, y en el 1844 animará a los Serra, los Plandolit y, muy especialmente a Manuel Girona i Agrafel, para lanzar el Banco de Barcelona que gracias a estudios posteriores sabemos de forma definitoria que, casi en su totalidad, fue financiado por capitales indianos y que tuvo un importante rol en el «blanqueo» de dichos fondos, muchos de los cuales provenían del tráfico de esclavos. El Gobierno concedió el privilegió al nuevo banco de emitir moneda, esta tenía que ser en pactado trance con la corona en unas gestiones que se gestaron durante los veranos del 43 y 44 .

Ya constituido y con capital para acometer inversiones, el nuevo financiador se fijará como objetivo el desarrollo de los ferrocarriles, astilleros, puertos, puentes, canales y carreteras, así como 
del industrialismo en Catalunya. Un desarrollo que Xifré ya había visto con sus propios ojos y trabajado con sus manos en América y que quiere ahora para su patria. No será, pues, una casualidad que la primera gran obra del Banco de Barcelona sea, entre otras, la construcción de un fracasado, en sus primeros años, canal del Urgel, como lo fueron también los transportes de mercancías por ferrocarril.

Xifré también copará ciertas esferas de la vida pública: será diputado en las Cortes (1850-51), uno de los pocos empresarios de entonces (también hoy sería una rara avis), ocupará un puesto dentro del consejo de la ciudad de Barcelona donde se le propondrá ser alcalde en varias ocasiones y será miembro, muchas veces fundador, de diversas instituciones que hoy configuran los principales pilares de la sociedad civil catalana como el Institut Agrícola Català de Sant Isidre o Foment del Treball, dos de las asociaciones de patronos más antiguas de Europa. Como hizo con el ingeniero Robert Fulton — que diseñará el primer buque comerciante propulsado por vapor y también el submarino de guerra Nautilus en aguas del Hudson-, ayudará a Monturiol a financiar sus experimentos con el Ictíneo, y financiará las investigaciones de Mariano Cubí sobre la entonces ya considerada protociencia de la frenología. Xifré fue por tanto un provocador, un librepensador, un visionario, un benefactor de la ciencia y la tecnología, un comerciante que puso su talento y energía al servicio de hacer cosas y ayudar hacer cosas.

Xifré fue también un influyente masón, de hecho pueden observarse muchos detalles masónicos en la fachada de los famosos porxos, y se dice que su influencia fue notable en la elaboración del texto de la constitución de la primera república redactada por aquel eterno embajador, breve Presidente de gobierno y caustico masón Salustiano Olózaga en Paris. Xifré, como decíamos al inicio participó de manera directa en la elaboración de las leyes del Estado de Nueva York, ¿cuán profunda fue su influencia sobre Olózaga en la redacción de la Constitución de la que sería la Primera República española?, es aún una de las cuestiones a investigar sobre el personaje y también sobre un periodo en la historia de España que sería clave. Hoy la embajada de España en Paris sigue impertérrita en la hoy precisamente Rue Olózaga, que era apodado por los parisinos como el tragón de los Campos Elíseos, por ser un exquisito y 
hambriento gourmet, con quién Xifré, en extremo austero y frugal, tuvo siempre muy buenos tratos.

La hoy demasiado desconocida historia del emprendedor Xifré i Casas, ya insinuada en su momento por el pedagógico historiador Vicens Vives, nos ha de hacer reflexionar sobre el papel determinante que tienen las personas con carácter, sus ideas y su capacidad de liderazgo, a la hora de cambiar el mundo y reflexionar sobre cuáles son las mejores instituciones y el marco adecuado para que este tipo de caracteres puedan eclosionar con mayor facilidad todo su potencial. En buena parte depende de ello la prosperidad futura de todos nosotros. 